\title{
Discussion: On the distinct phenomena of suffusion and suffosion
}

\author{
R. J. FANNIN*, P. SLANGEN*, A. MEHDIZADEH†, M. M. DISFANI†, A. ARULRAJAH† and R. EVANS $\dagger$
}

A valuable conceptual framework for the characterisation of seepage-induced internal instability was provided in the article under discussion, particularly for the 'suffusion and suffosion' phenomena. A few modifications are suggested here to clarify the definitions in the original paper.

ICE Publishing: All rights reserved

\section{NOTATION}

post-suffosion void ratio

$e_{\mathrm{c}}$ post-suffusion void ratio

$H$ thickness of soil

$H_{i}$ thickness of each layer

$i_{\text {av }} \quad$ average hydraulic gradient

$k$ hydraulic conductivity

$k_{\text {eq }}$ equivalent hydraulic conductivity

$k_{i} \quad$ local hydraulic conductivity

$\varepsilon_{\mathrm{v}} \quad$ volumetric deformation

\section{CONTRIBUTION BY A. MEHDIZADEH, M. M. DISFANI,}

\section{A. ARULRAJAH AND R. EVANS}

Fannin \& Slangen (2014) provided a valuable and clear conceptual framework for the characterisation of seepageinduced internal instability, particularly for the 'suffusion and suffosion' phenomena. The original paper aims to reduce the existing conflictions and ambiguities in the literature and create consistent terminology, which has been attempted in the past by other researchers such as Richards \& Reddy (2007) and Ke \& Takahashi (2014).

Fannin \& Slangen (2014) identified a linear relation between hydraulic gradient and discharge velocity for $i_{\text {av }}<2.9$ (Fig. 1(b)), which in turn indicates a constant value for hydraulic conductivity $k$. For $i_{\mathrm{av}} \geq 2 \cdot 9$, a disproportionate increase in discharge velocity with hydraulic gradient leads to an increase in $k$. The relationship between discharge velocity and hydraulic gradient shown in Fig. 1(b) can be divided into three distinct parts. The slope of the graph $(k)$ increases slightly from part $1\left(i_{\text {av }}\right.$ from 0 to $\left.1 \cdot 3\right)$ to part 2 ( $i_{\text {av }}$ from $1 \cdot 3$ to $2 \cdot 9$ ), and then jumps excessively $\left(i_{\text {av }} \geq 2 \cdot 9\right)$. Therefore, the hydraulic conductivity is not constant for $i_{\mathrm{av}} \leq$ 2.9. In the authors' view, Fannin \& Slangen's interpretation of change of $i_{\text {av }}$ for Fig. 1(a) is reasonable, but it can be modified for Figs 1(b) and 1(c) as noted above.

Fannin \& Slangen (2014) identified suffusion as a phenomenon accompanied by an increase of $k$. Although this raises no doubts at first glance, interestingly there are studies claiming that $k$ decreases or even remains constant during suffusion. For example, Bendahmane et al. (2008) noted that permeability decreased by a factor of ten when erosion was initiated. Xiao \& Shwiyhat (2012) reported a reduction in permeability with progression of suffusion in gap-graded soils. No permeability change was reported as a result of suffusion in poorly graded soils. It appears that the

Published online at www.geotechniqueletters.com on 4 August 2015.

*University of British Columbia, Vancouver, Canada

$\dagger$ Department of Civil and Construction Engineering, Swinburne University of Technology, Melbourne, Australia

tDepartment of Infrastructure Engineering, University of Melbourne, Melbourne, Australia change of $k$ in the suffusion process is heavily dependent on the clogging phenomena. After washing the particles, the local hydraulic conductivity increases and if those washed particles settle or clog somewhere else in the soil, the local hydraulic conductivity of that region decreases. The result of such changes in local hydraulic conductivities provides an equivalent hydraulic conductivity $\left(k_{\text {eq }}\right)$, which may be higher or lower than the initial magnitude or may remain constant after the suffusion process.

This variation can be postulated by an equivalent permeability formula

$$
k_{\mathrm{eq}}=\frac{\Sigma H}{\Sigma H_{i} / k_{i}}
$$

Fannin \& Slangen (2014) attributed volumetric contraction or reduction to one of the distinctive features of the suffosion phenomenon. Ke \& Takahashi (2014) stated that 'change of void ratio is caused by the loss of fines $\left(\Delta V_{\mathrm{f}}\right)$ and possible intergranular re-arrangement $(\Delta V)$ '. They showed that changes in void ratio are equal to $\varepsilon_{\mathrm{v}}\left(1+e_{\mathrm{c}}\right)$ in which $\varepsilon_{\mathrm{v}}$ is considered positive if the specimen shows contractive behaviour or negative if it shows dilative behaviour during suffusion. Therefore, the post-suffosion void ratio is obtained from

$$
e=e_{\mathrm{c}}-\varepsilon_{\mathrm{v}}\left(1+e_{\mathrm{c}}\right)
$$

Fannin \& Slangen (2014) accurately explained the fluidisation phenomenon for upward seepage flow. Nevertheless, heave and loss of fine particles can occur simultaneously in upward flow. In addition, Ke \& Takahashi (2014) demonstrate that dilative behaviour can also occur after suffusion. It seems that more clarification is needed in relation to the suffosion phenomenon, especially regarding the type of volumetric deformation.

To summarise, the following modifications are suggested to make the definitions in the paper clearer.

- Suffusion should be characterised as seepage-induced mass loss without a change in volume and with or without any change in general hydraulic conductivity but with a change in local hydraulic conductivity.

- Suffosion should be characterised as seepage-induced mass loss accompanied by a change in volume and a change in hydraulic conductivity.

\section{AUTHORS' REPLY}

We thank the discussers for their interest in our publication and the suggestion of two possible modifications to the terminology.

We proposed the term suffusion be characterised as 'seepage-induced mass loss without change in volume, accompanied by an increase of hydraulic conductivity'. We agree with the discussers that suffusion is a localised 
phenomenon, whereby wash-out of particles results in mass loss and yields an increase in local hydraulic conductivity. We also accept that seepage-induced transport of the washed out particles may lead to their entrapment at a different location within the porous medium, however we believe this clogging action to represent a separate and distinct localised phenomenon.

We proposed the term suffosion be characterised as 'seepage-induced mass loss accompanied by a reduction in volume and a change in hydraulic conductivity'. The discussers report the findings of $\mathrm{Ke} \&$ Takahashi (2014), who observed a dilative response in test specimens that have exhibited suffosion when subject to drained shear. However, we similarly believe that the shear-induced dilative response is a separate and distinct phenomenon that is unrelated to seepage flow.

\section{REFERENCES}

Bendahmane, F., Marot, D. \& Alexis, A. (2008). Experimental parametric study of suffusion and backward erosion. J. Geotech. Geoenviron. Engng 134, No. 1, pp. 57-67.

Fannin, R. J. \& Slangen, P. (2014). On the distinct phenomena of suffusion and suffosion. Géotech. Lett. 4, No. 4, pp. 289-294, http://dx.doi.org/10.1680/geolett.14.00051.

Ke, L. \& Takahashi, A. (2014). Experimental investigations on suffusion characteristics and its mechanical consequences on saturated cohesionless soil. Soils and Found. 54, No. 4, pp. 713-730.

Richards, K. S. \& Reddy, K. R. (2007). Critical appraisal of piping phenomena in earth dams. Bull. Engng Geol. Environ. 66, No. 4, pp. 381-402.

Xiao, M. \& Shwiyhat, N. (2012). Experimental investigation of the effects of suffusion on physical and geomechanic characteristics of sandy soils. Geotech. Test. J. 35, No. 6, pp. 890-900. 